\title{
Cryopreservation enhances embryogenic capacity of Gentiana cruciata (L.) suspension culture and maintains (epi)genetic uniformity of regenerants
}

\author{
Anna Mikuła $\cdot$ Karolina Tomiczak • \\ Jan J. Rybczyński
}

Received: 24 September 2010/Revised: 15 November 2010/ Accepted: 2 December 2010/Published online: 15 December 2010 (C) The Author(s) 2010. This article is published with open access at Springerlink.com

\begin{abstract}
The embryogenic cell suspension culture of Gentiana cruciata, cryopreserved by the encapsulation/ dehydration method, survived both short- $(48 \mathrm{~h})$ and longterm (1.5 years) cryostorage with more than $80 \%$ viability. To assess the influence of cryotreatments on the embryogenic potential, a proembryogenic mass was encapsulated and exposed to the following treatments: (1) osmotic dehydration (OD), (2) OD + air desiccation (AD) and (3) $\mathrm{OD}+\mathrm{AD}+$ cryostorage (LN). The somatic embryogenesis efficiency increased ten times after osmotic dehydration. The $\mathrm{AD}$ and $\mathrm{LN}$ cryotreatments did not cause any significant alterations in somatic embryo production. We monitored the (epi)genetic stability of 288 regenerants derived from: non-cryotreated, short-term, and long-term cryostored tissue using metAFLP markers and ten primer combinations. Changes in the sequence and DNA methylation levels were studied by subjecting the DNA to digestion with two pairs of isoschisomer restriction enzymes (KpnI/MseI and Acc65I/MseI). Two new AFLP unique DNA fragments at the DNA sequence level, with no differences at the methylation level, were found between regenerants derived from cryopreserved tissue, compared with the non-cryotreated controls. The Acc65I/MseI methylation levels for the three groups of regenerants were not significantly different. Cluster analysis was capable of identifying a number of sub-clusters. Only one of the subclusters comprises almost all regenerants derived from
\end{abstract}

Communicated by A. Altman.

A. Mikuła $(\square) \cdot$ K. Tomiczak · J. J. Rybczyński Botanical Garden-Center for Biological Diversity Conservation, Polish Academy of Sciences, ul. Prawdziwka 2, 02-973 Warsaw, Poland e-mail: amikula@obpan.pl non-cryotreated and short-term cryostored tissue. Plantlets derived from long-term cryostored tissue were grouped into separate clusters. The observed AFLP alterations did not appear to be associated with the use of cryopreservation, but were probably related to the process of in vitro culture.

Keywords Encapsulation/dehydration - metAFLP . Osmotic dehydration - Short- and long-term cryostorage . Somatic embryogenesis

\section{Introduction}

Cryo-conservation protocols have been established for many vegetatively propagated species and introduced into the world genebanks (Engelmann 2004). The ultralow temperature of liquid nitrogen efficiently stops the metabolic processes. Plant material is then capable to be preserved for a theoretically unlimited period of time (Walters et al. 2004). However, the cryotreatment, cryostorage or post-thaw manipulations can cause stress-induced factors and such factors may lead to morphogenic or genetic alterations.

The majority of studies prove that cryopreservation does not affect embryogenic potential of calli or suspension culture, which has been documented for example for a majority of 39 independent embryogenic lines of Hevea brasiliensis (Lardet et al. 2007). The increase in the embryogenic capacity after cryopreservation becomes visible for the first time in Citrus deliciosa (Aguilar et al. 1993). Usually, the regeneration enhancement is considered as the final result of the cryopreservation procedure. So far, the phenomenon was ascertained for embryogenic tissue of: Festuca arundinacea, Lolium spp. (Wang et al. 1994), Hevea brasiliensis (Engelmann et al. 1997), Vitis vinifera 
(Wang et al. 2002) and Cyclamen persicum (Winkelmann et al. 2004). Investigations are needed to determine whether the regeneration enhancement effect is caused by pretreatment, freezing, or by a combination of the two.

The assessment of plant genetic uniformity to validate newly established cryopreservation protocols has been a subject of increasing interest (Harding 2004). So far, only some evidence of genetic alterations after cryopreservation treatment of in vitro-derived plant material was shown. Changes at the DNA sequence level seem to appear sporadically, or accidentally, and most frequently are carried on by single specimens and characterized by one (Ahuja et al. 2002; Martín and González-Benito 2005; Dixit et al. 2003; Moukadiri et al. 1999; Sánchez et al. 2008) or two new markers (Martín and González-Benito 2009; Urbanová et al. 2006). However, experiments conducted on 6 different genotypes of Carica papaya showed varying levels of genomic DNA modifications (up to 10.07\%) covering 14 changes (Kaity et al. 2008). Genetic stability of regenerants recovered from cryopreserved plant material is also associated with DNA methylation changes which were ascertained in all experiments conducted up till now. Studies of Fragaria gracilis (Hao et al. 2002a), Citrus sinensis (Hao et al. 2002b), Malus pumila (Hao et al. 2001), Ribes (Johnston et al. 2009), Carica papaya (Kaity et al. 2008, 2009), Humulus lupulus (Peredo et al. 2008), Prunus dulcis (Channuntapipat et al. 2003) and Arabidopsis thaliana (Wang and He 2009) showed detectable differences. These differences demonstrate the complexity of the processes assisting cryopreservation and influencing cell culture variation.

Several molecular markers were used to analyze genetic stability of cryopreserved plant material (Harding 2004). Currently, application of randomly amplified polymorphic DNA (RAPD) and amplified DNA methylation polymorphism (AFLP) is most frequently noticed. However, in terms of a study of structural and methylation DNA changes, more than one molecular marker is applied, e.g. RAF (randomly amplified DNA fingerprinting) and AMP (amplified DNA methylation polymorphism) for Carica papaya (Kaity et al. 2008, 2009), AFLP (amplified fragment length polymorphism) and MSAP for Malus pumila and Fragaria gracilis (Hao et al. 2001, 2002a), RAPD and MSAP for Citrus sinensis (Hao et al. 2002b) or RAPD, AFLP and MSAP for Humulus lupulus (Peredo et al. 2008). The sensitivity of detecting changes, in both the structure and methylation of DNA, was improved by subjecting the DNA to digestion separately with HpaII, Bsp143I (relatively methylation sensitive), MspI and MboI (methylation insensitive) restriction endonucleases before RAPD-PCR (Channuntapipat et al. 2003). This latter comparison of methylation (in)sensitive isoschisomers resulted in detectable differences due to cryopreservation and in vitro culture, at the sequence and DNA methylation levels. Recently, a new variant of the metAFLP approach was introduced that is dedicated to simultaneous quantification of sequence, and site DNA methylation changes within the sequence recognized by the Acc65I/MseI and KpnI/MseI pairs of endonucleases. Acc65I and KpnI are isoschizomers that differ in their sensitivity to site DNA methylation. Acc65I is insensitive to $\mathrm{dcm}$ methylation, although its activity is blocked by both dam and $\mathrm{CpG}$ methylation. KpnI is insensitive to all forms of methylation (Bednarek et al. 2007). In the present study, a new variant of metAFLP was employed to screen for changes in genomic DNA structure and DNA methylation patterns.

The gentian cell suspension cultures are an invaluable long-term source of numerous somatic embryos (Mikuła et al. 2005b, 2008; Fiuk and Rybczyński 2008), totipotent protoplasts (Fiuk and Rybczyński 2007), and embryogenic tissue for the production of interspecies somatic hybrids and transformed plants (Rybczyński et al. 2008). This type of culture had a considerably higher effectiveness of somatic embryogenesis (Mikuła et al. 2005b) than the agar culture (Mikuła and Rybczyński 2001). The somatic embryos could also be received regularly for more than 11 years for G. tibetica (Mikuła et al. 2008), and over 3 years for G. cruciata (Mikuła et al. 2005b). Nonetheless, the reduction in embryogenic competence is clearly visible with time (Mikuła et al. 2008). After a 12.5-year maintenance, the somatic embryo productivity of the $G$. tibetica suspension culture decreased by about 53 times. Our previous studies showed that cryopreservation is a reliable approach to preserve the viability and recovery of gentian cell suspension cultures. Our previous studies also showed that the encapsulation/dehydration protocol is the most useful among the three studied methods of cryo-conservation (Mikuła 2006; Mikuła et al. 2008). The aims of the current studies were (1) to assess the influence of the subsequent steps of cryopreservation by encapsulation/ dehydration on the G. cruciata somatic embryo production and (2) to evaluate the uniformity of regenerants with the help of metAFLP analysis.

\section{Materials and methods}

Plant material and cryopreservation procedure

Experiments were carried out on proembryogenic mass (PEM) derived from the 2- and 3.5-year-old suspension culture of $G$. cruciata L. The induction and maintenance were elsewhere described (Mikuła et al. 2005a). The cell suspension was subcultured every 7 days. For cryopreservation by encapsulation/dehydration, the cell aggregates were encapsulated in $3 \%(\mathrm{w} / \mathrm{v})$ sodium alginate (Sigma) 
(Mikuła et al. 2008). Osmotic dehydration (OD) was conducted by increasing the concentration of sucrose from 0.3 , $0.5,0.75$ ( $48 \mathrm{~h}$ for each) to $1.0 \mathrm{M}$ ( $1 \mathrm{day}$ ). Alginate beads were then harvested and surface dried in a laminar flow chamber at room temperature for $5 \mathrm{~h}$ (AD) and loaded into $2-\mathrm{ml}$ cryovials (15 beads per vial). Cryovials were immersed directly into LN where they remained for $48 \mathrm{~h}$ or 1.5 year. The scheme of the cryopreservation procedure, including thawing and recovery of suspension cultures, is shown in Fig. 1.

Cell survival, after short- $(48 \mathrm{~h})$ and long-term (1.5 year) cryostorage, was determined in two independent experiments ( 9 replicates of 10 beads in each). The 2,3, 5-triphenyltetrazoliumchloride (TTC) reduction test, as previously described for gentian cultures by Mikuła et al. (2006), was used. Encapsulated cells were stained immediately after embedding (as a control) and 2 days after thawing. The biomass growth of PEM after 4 weeks of post-thawing culture (the first 2 weeks in agar and later in liquid culture) (Mikuła et al. 2008) was assessed (1 replicate $=10$ beads). Analyses were performed in two independent experiments (of 3 repetitions). The results were estimated using a single factor analysis of variance (ANOVA) and a Fisher's least significant difference test (LSD) using Statgraphics Plus software. Significance is stated at $P<0.05$.

Experimental design for embryogenic productivity assessment

To assess the influence of the cryotreatments on the embryogenic potential, the PEM derived from the 3.5-year- old suspension culture was encapsulated and exposed to the following treatments: (1) osmotic dehydration (OD), and (2) $\mathrm{OD}+$ air desiccation (AD) and (3) OD + AD + $48 \mathrm{~h}$ storage in liquid nitrogen (LN) (Fig. 1). After each cryotreatment step, the recovery of cultures was performed. After 6 weeks, the PEM derived from recovered suspension cultures was implanted onto the agar regeneration medium supplemented with $0.5 \mathrm{mg} / \mathrm{L}$ gibberellic acid, $1.0 \mathrm{mg} / \mathrm{L}$ kinetin and $80.0 \mathrm{mg} / \mathrm{L}$ adenine sulfate (Mikuła et al. 2005a). Cell aggregates from non-encapsulated, nontreated and non-frozen suspension culture were treated as the control.

The efficiency of somatic embryogenesis, expressed as a number of cotyledonary stage embryos per $50 \mathrm{mg}$ of PEM, was determined in two independent experiments (12 Petri dishes for each). Data were recorded in the sixth week, after the transfer of PEM onto regeneration medium. The results were estimated using a single-factor analysis of variance (ANOVA) and a Fisher's least significant difference test (LSD) using Statgraphics Plus software. Significance is stated at $P<0.05$.

Plant material and experimental design for molecular analysis of regenerants

For molecular analysis, the somatic embryo-derived regenerants obtained from: control tissue i.e. non-cryotreated and non-cryostored PEM (NC), short-term (48 h) (SC) and long-term (1.5 year) cryostored PEM (LC) were employed (Fig. 2). NC and SC regenerants derived from 3.5-year-old cell suspension, LC regenerants derived from 2-year-old cell suspension. A 3.5-year-old suspension culture of
Fig. 1 Scheme of the cryopreservation procedure for the Gentiana cruciata suspension culture (white arrows) and sources of somatic embryos for assessment of the influence of cryotreatment on somatic embryogenesis efficiency (black arrows). Osmotic dehydration (OD) was conducted by increasing the concentration of sucrose from $0.3,0.5,0.75 \mathrm{M}$ (48 $\mathrm{h}$ for each) to $1.0 \mathrm{M}$ (1 day)

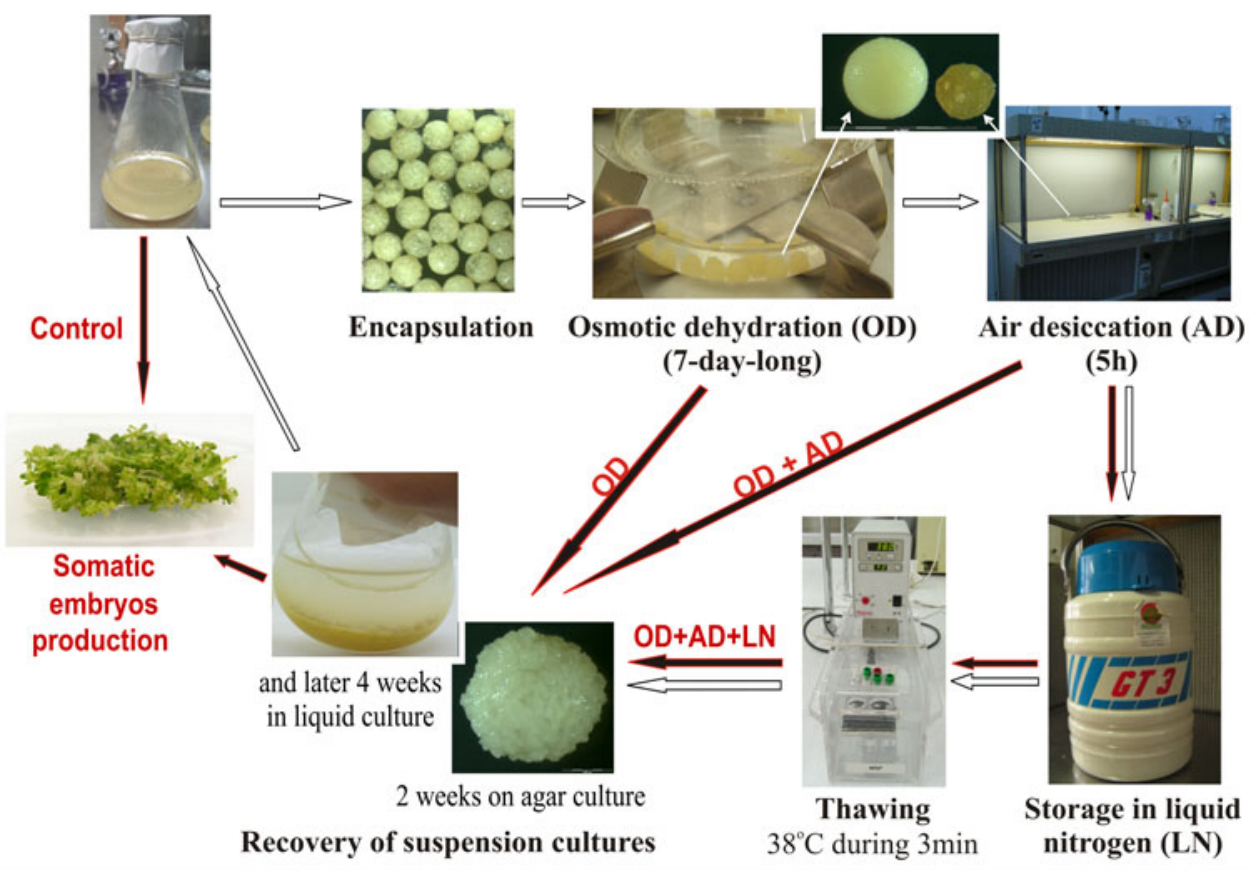


Fig. 2 The schematic diagram representing plant material development for molecular studies. PEM proembryogenic mass, $N C, S C L C$ regenerants derived from: non-cryotreated, short- and long-term cryostored PEM, respectively

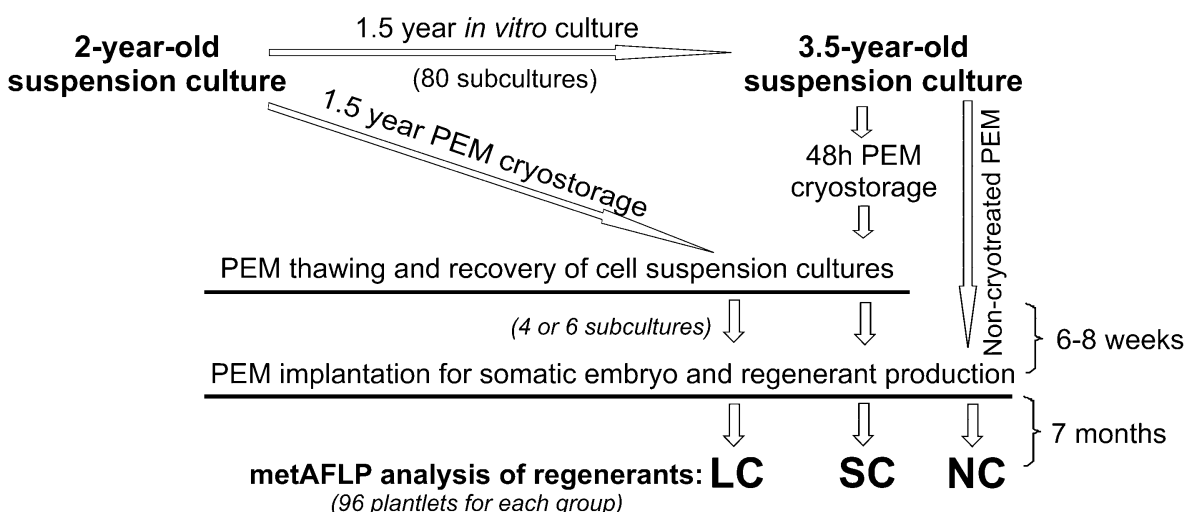

(96 plantlets for each group)
G. cruciata was 80 times more subcultured than the 2-yearold one. The regenerants were cultured on the half-strength MS basal medium. A 9-month-old plantlets, having at least 10 leaves, were subjected for molecular analysis. Regenerants originated from two independent PEM implantations on agar regeneration medium, within a 2-week interval (after 4 and 6 subcultures of recovered suspension cultures). Each implanting repetition included 48 plantlets (a total of 288 regenerants for NC, SC and LC).

Modified analysis of amplified fragment length polymorphism (metAFLP)

Total genomic DNA was isolated from leaves using the Dneasy Plant Mini Kit (Qiagen, GmbH, Hilden, Germany) according to the manufacturer's instructions, following the methylation-sensitive AFLP previously described (Bednarek et al. 2007). Each DNA sample, representing an individual regenerant, was briefly placed in two independent vessels. One part of the sample was digested with KpnI/MseI, while the other with Acc65I/MseI, following by adaptor ligation and pre-selective amplification steps (Table 1). The products of the non-selective PCR under-

Table 1 Adapters and metAFLP oligomer sequences

\begin{tabular}{ll}
\hline Adapters/primers & Sequence $5^{\prime} \rightarrow 3^{\prime}$ \\
\hline Acc65I adapter 1 & CTC GTA GCA TGC GTA CA \\
Acc65I adapter 2 & GTA CTG TAC GCA TGC TAC \\
KpnI adapter 1 & CTC GTA GCA TGC GTA CAG TAC \\
KpnI adapter 2 & TGT ACG CAT GCT AC \\
Mse I adapter 1 & TAC TCA GGA CTC ATC \\
MseI adapter 2 & GAC GAT GAG TCC TGA G \\
Acc65I/KpnI & GCA TGC GTA CAG TAC C \\
pre-selective primer & \\
MseI pre-selective primer & GAT GAG TCC TGA GTA AC \\
\hline
\end{tabular}

went a selective amplification step using the following primer combinations: CpG-GAC/M-CGC, CpXpG-AGA/ M-CTG, CpXpG-AGC/M-CGT, CpG-GGC/M-CAA, CpGGAG/M-CGA, CpXpG-AGG/M-CAC, CpG-GCA/M-CCG, CpG-GGT/M-CAT, CpXpG-AGT/M-CCC, CpXpG-TGC/ M-CAG. Basic primer sequences were 5'-CAT GCG TAC AGT ACC-3' for CpG- and CpXpG- and 5'-GAT GAG TCC TGA GTA A- $3^{\prime}$ for $\mathrm{M}-$. The $\mathrm{CpG}$ and $\mathrm{CpXpG}$ primers were P32 labeled at their $5^{\prime}$-ends.

PCR products were denatured in an $80 \%$ formamide loading buffer, and separated in $6 \%$ denaturing polyacrylamide gel following by overnight exposition to X-ray films at $-70^{\circ} \mathrm{C}$.

\section{Molecular data analysis}

The banding patterns, identified in both KpnI/MseI and Acc65I/MseI AFLP platforms, were juxtaposed based on the common bands and treated as a single profile. Thus, bands missing in one platform and present in the other were also juxtaposed. This juxtaposition resulted in a profile with the same number of markers in both platforms (Bednarek et al. 2007). The AFLP patterns were recorded as 0-1 binary matrices, where " 1 " indicates the presence and " 0 " the absence of a given fragment following by statistical analysis. The methylation restriction points for Acc65I/MseI were calculated as a number of methylated loci (bands present on the KpnI/MseI platform and absent on Acc65I/MseI platform) divided by the total number of bands expressed by percentage. GenAlex 6.2 software was used to calculate the number of AFLP fragments. Measures of genetic uniformity among regenerant samples were determined using the Jaccard dissimilarity coefficient. Genetic XIStat v.2009.04 excel add-in software was used to draw the dendrogram (UPGMA, Jaccard) and to perform principle coordinate analysis (PCoA). 


\section{Results}

PEM survival and suspension culture recovery after short-term and long-term cryostorage

Determined by TTC test, the survival of PEM stored in LN for $48 \mathrm{~h}$ and for 1.5 years reached $82 \%$ (Table 2). Cryotreatments and liquid nitrogen exposure did not change the ability of the tissue to culture recovery. The biomass growth, after the $48 \mathrm{~h}$ and 1.5 years of PEM cryostorage, was maintained on the level assessed for control suspension culture (Table 2). After 4 weeks of agar/liquid (2 weeks for each), post-thawing culture about $8 \mathrm{~g}$ fresh weight per 10 beads for each treatment were achieved.

Embryogenic capacity of 3.5-year-old cell suspension culture

Six-week-old suspension cultures, recovered after the (OD; $\mathrm{OD}+\mathrm{AD} ; \mathrm{OD}+\mathrm{AD}+\mathrm{LN}$ ) cryotreatments, were used for somatic embryo production. The productivity of noncryotreated 3.5-year-old suspension culture was 9 somatic embryos from $50 \mathrm{mg}$ PEM (Fig. 3). OD treatment increased the somatic embryogenesis process resulting in 90 somatic embryos per $50 \mathrm{mg}$ PEM. Air desiccation and LN treatment did not further affect the embryogenic efficiency.

\section{AFLP analysis of the regenerants}

In total, both $\mathrm{KpnI} / \mathrm{Mse} \mathrm{I}$ and Acc65I/MseI platforms generated 560 clearly visible AFLP markers shared among the sets. However, when calculations were performed using either the KpnI/MseI or the Acc65I/MseI AFLP platform, there were from 533 to 554 bands shared among the NC, $\mathrm{SC}$ and LC sets of regenerants (Table 3). The KpnI/MseIbased platform allowed for the identification of 499 bands appearing with a frequency greater than 5\% among regenerants of the NC set, 528 among SC, and 515 among LC. In the case of Acc65I/MseI digests, 531 AFLP bands

Table 2 PEM survival and fresh weight growth after 4 weeks of post-thawing culture for $48 \mathrm{~h}$ and 1.5-year PEM cryostorage

\begin{tabular}{llll}
\hline & \multirow{2}{*}{$\begin{array}{l}\text { Control } \\
\text { (encapsulated }\end{array}$} & \multicolumn{2}{l}{ PEM after LN storage for } \\
\cline { 3 - 4 } & PEM) & $48 \mathrm{~h}$ & 1.5 years \\
\hline PEM survival (\%) & - & $81.50 \pm 9.14 \mathrm{a}$ & $82.9 \pm 12.01 \mathrm{a}$ \\
$\begin{array}{llll}\text { Fresh weight growth } \\
\text { (g) }\end{array}$ & $8.14 \pm 1.20 \mathrm{a}$ & $8.27 \pm 1.05 \mathrm{a}$ & $8.03 \pm 1.09 \mathrm{a}$ \\
& & &
\end{tabular}

Values marked by the same letter are not significantly different at $P<0.05$ (LSD test). Data were recorded from two independent experiments with nine or three replicates (10 beads in each) for assessment of PEM survival or fresh weight growth, respectively

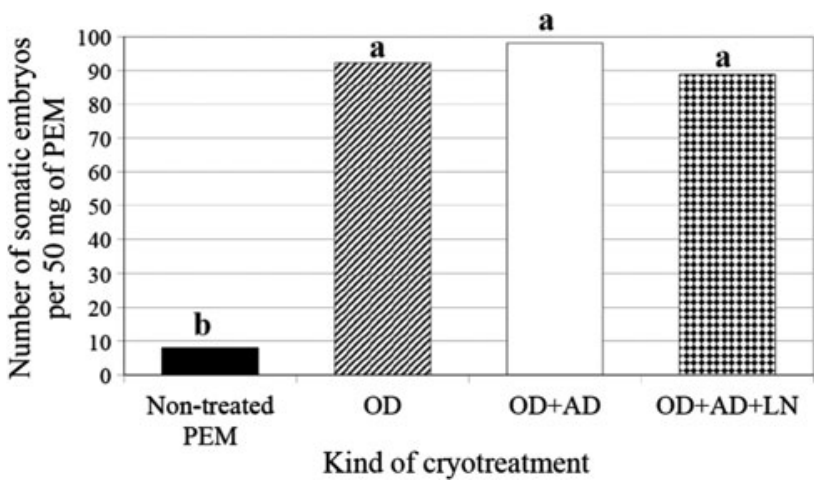

Fig. 3 Effect of PEM cryotreatment on somatic embryo production on agar regeneration medium after 6 weeks of culture. PEM proembryogenic mass, $O D$ osmotic dehydration, $A D$ air desiccation, $L N$ storage in liquid nitrogen (48 h). Values marked by the same letter are not significantly different at $P<0.05$ (LSD test). Data were recorded from two independent experiments with 12 individual plates, each treated as a replicate

Table 3 Arrangement of band pattern in $\mathrm{KpnI} / \mathrm{Mse} \mathrm{I}$ and Acc65I/MseI AFLP platforms for the three sets of $G$. cruciata regenerants derived from: non-cryotreated PEM (NC), short- (SC) and long-time (LC) cryostored PEM

\begin{tabular}{|c|c|c|c|c|c|c|}
\hline \multirow[t]{3}{*}{ AFLP fragments } & \multicolumn{6}{|c|}{ Group of regenerants } \\
\hline & \multicolumn{3}{|c|}{ KpnI/MseI } & \multicolumn{3}{|c|}{ Acc65I/MseI } \\
\hline & $\mathrm{NC}$ & $\mathrm{SC}$ & $\mathrm{LC}$ & $\mathrm{NC}$ & $\mathrm{SC}$ & $\mathrm{LC}$ \\
\hline No. AFLP fragments & 533 & 554 & 548 & 551 & 553 & 551 \\
\hline $\begin{array}{l}\text { No. AFLP fragments } \\
\text { with a frequency } \geq 5 \%\end{array}$ & 499 & 528 & 515 & 531 & 529 & 531 \\
\hline No. new AFLP fragments & 0 & 2 & 0 & 0 & 2 & 0 \\
\hline
\end{tabular}

were amplified for both $\mathrm{NC}$ and $\mathrm{LC}$ regenerants, and 529 for SC set. Two new DNA fragments distinguished 98 SC regenerants from the $196 \mathrm{NC}$ and LC regenerants (Table 3). Between plantlets, no changes in the methylation level were found. The percentage of methylated loci varied between $16.61 \%$ for NC and LC regenerants, and $16.88 \%$ for SC (Table 4).

The UPGMA analysis (Fig. 4) was capable of identifying a number of sub-clusters, but only two of the them encompassed most of the regenerants. One of the subclusters was comprised of almost all the plantlets derived from non-cryotreated and short-term cryostored tissue, while the other sub-cluster included most of the LC regenerants, independent of the AFLP platform used. The Jaccard's dissimilarity genetic distance between the subclusters was $0.27(\mathrm{KpnI} / \mathrm{MseI})$ and 0.34 (Acc65I/MseI). Although agglomeration analyses failed to separate $\mathrm{NC}$ and SC sets, principle coordinate analysis (PCoA) grouped all the regenerants according to the way they were derived, and grouped the regenerants independently of the AFLP 
Table 4 Comparison of the methylation restriction points for Acc65I/ $M s e I$ for the three sets of $G$. cruciata regenerants derived from: noncryotreated PEM (NC), short- (SC) and long-time (LC) cryostored $\mathrm{PEM}( \pm \mathrm{SD})$

\begin{tabular}{llll}
\hline & \multicolumn{4}{l}{ Group of regenerants } \\
\cline { 2 - 4 } & NC & SC & LC \\
\hline $\begin{array}{c}\text { Percentage of } \\
\text { methylated loci }\end{array}$ & $16.61 \pm 0.11$ & $16.88 \pm 0.86$ & $16.61 \pm 0.42$ \\
\hline
\end{tabular}

platform used for the calculations (Fig. 5). However, this grouping was more clearly visible on the Acc65I/MseI (Fig. 5b) than on the KpnI/MseI (Fig. 5a) platform.

\section{Discussion}

We developed a reliable encapsulation/dehydration protocol for cryopreservation of gentian cell suspensions (Mikuła et al. 2008), which offers more than $80 \%$ survival of PEM. The protocol also provides very fast, simple, and reproducible recovery of suspension cultures during a 4-week period. Our studies showed that liquid nitrogen did not affect the re-growth of suspension cultures and did not influence the genome size in PEM and in regenerants (Mikuła et al. 2008). At present, the influence of subsequent steps of the encapsulation/dehydration procedure on the embryogenic capacity of $G$. cruciata cell suspension culture and metAFLP analysis of regenerants derived from short-term and long-term cryostored PEM were undertaken.

Influence of cryopreservation on the embryogenic potential

The results presented here show that the G. cruciata suspension culture, recovered after cryopreservation by encapsulation/dehydration, regenerated a higher number of somatic embryos than unfrozen culture. There are only a few other references to the same problem and they support our findings. Wang et al. (1994) obtained a 28\% regeneration frequency from the cell clusters of Festuca arundinacea, while the corresponding re-established suspension culture acquired an $82 \%$ regeneration capacity after cryopreservation. Moreover, more than a twofold higher plant regeneration frequency was observed for protoplasts isolated from suspension culture recovered after cryopreservation than from non-cryopreserved one. Cryopreservation promoted embryogenesis and subsequent plant germination of Vitis vinifera (Wang et al. 2002). The number of embryos increased from 106 before cryopreservation to 785 after freezing. Non-frozen and frozen tissues of Cyclamen persicum were sources of an average of 120-300, and 470 somatic embryos per gram, respectively (Winkelmann et al. 2004).

The fact that cryopreservation results in higher regeneration rates and is probably related to the selection of certain cell types. Selection seems to point towards embryogenic (totipotent) cells. These cells possess a more dense cytoplasm and contain less water (Häggman et al. 1998; Mikuła et al. 2005c). Consequently, embryogenic cells are more resistant to dehydration and cryopreservation. The phenomenon has been observed in proembryogenic masses of gentian suspension culture (Mikuła et al. 2005c). However, we found that the maximum growth of the embryogenic capacity of the G. cruciata cell suspension was reached following 7 days of osmotic dehydration of encapsulated PEM, in liquid medium supplemented with rising concentrations of sucrose (from 0.3, 0.5, 0.75 to $1.0 \mathrm{M}$ ). Somatic embryo productivity, from suspension culture recovered after this treatment, increased ten times. Similarly, dehydration treatment enabled encapsulated embryogenic cell suspensions of Vitis vinifera to increase the number of regenerated embryos more than fourfold (Wang et al. 2002). For this experiment, the two-step preculture (from 0.25 to $1.0 \mathrm{M}$ sucrose) was extended to 5 days. The subsequent steps of the encapsulation/dehydration method, i.e. air desiccation and freezing, did not
Fig. 4 Agglomeration (UPGMA, Jaccard) analysis of the NC, SC and LC sets of regenerants based on digested by $\mathrm{KpnI} / \mathrm{Mse} \mathrm{I}$ (a) and Acc65I/ MseI (b) AFLP platforms. The number of regenerants is given in parentheses. $N C, S C, L C$ regenerants derived from: noncryotreated, short- and longterm cryostored PEM, respectively

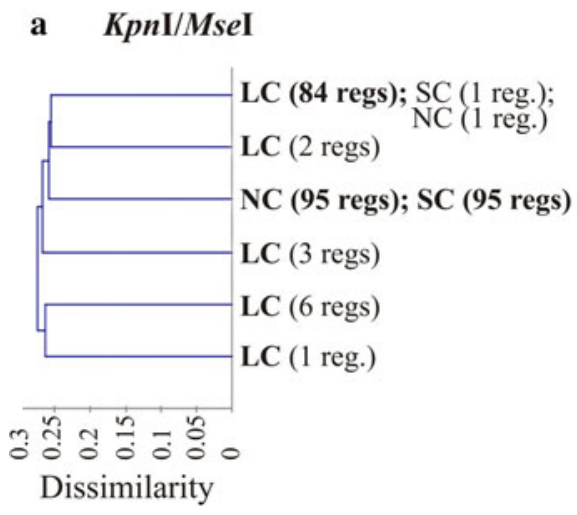

b Acc65I/MseI

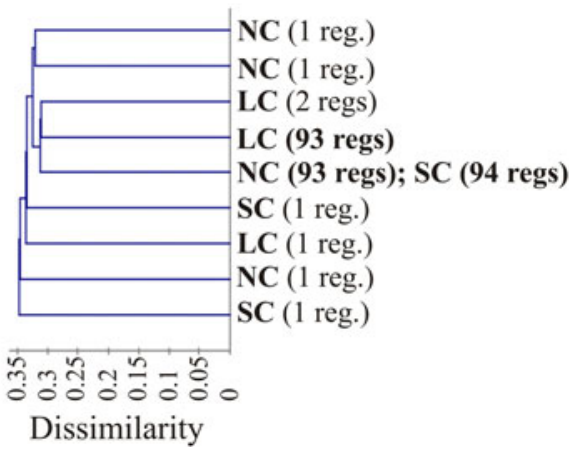


Fig. 5 Principle coordinate analysis (PCoA) of the $\mathrm{NC}, \mathrm{SC}$ and LC sets of regenerants based on the digested by KpnI/ MseI (a) and Acc65I/MseI (b) AFLP platforms. $N C, S C$, $L C$ regenerants derived from: non-cryotreated, short- and long-term cryostored PEM, respectively
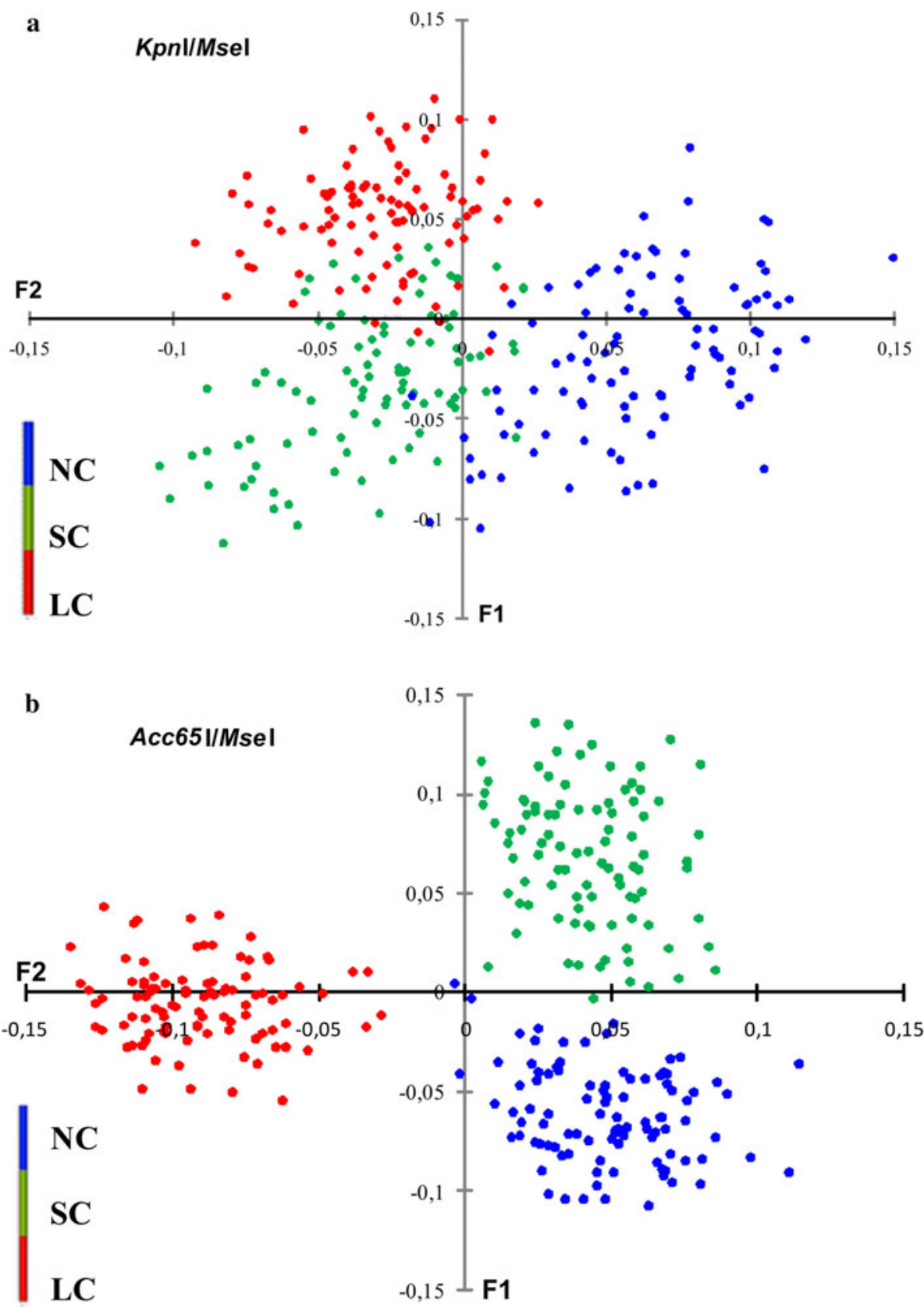

cause additional, significant alterations in embryogenic capacity of the G. cruciata suspension culture. In contrast, for Vitis vinifera, the embryogenic potential increased sevenfold after cryostorage (Wang et al. 2002).

It has been reported, for example, for Daucus carota or Festuca rubra, that somatic embryogenesis can be induced on primary explants (Kamada et al. 1993; Tanaka et al. 2009) or restored to long-term cultures (Zaghmout and Torello 1992), by the treatment with high levels of sucrose. In all the studies on cryopreservation, where elevation of embryogenic capacity was noticed, a prefreezing treatment with high concentrations of sucrose (Wang et al. 2002; Winkelmann et al. 2004; Engelmann et al. 1997; Aguilar et al. 1993) or sorbitol (Wang et al. 1994) was used. However, these treatments were employed only for a short time: from $1 \mathrm{~h}$ (Engelmann et al. 1997) to 3-4 days (Wang et al. 1994). The treatments at the most doubled the regeneration potential. In contrast, the encapsulation/ dehydration method, which requires a 5-7-day-long sucrose treatment, had 4 or 9 times more elevated somatic embryo production for Vitis vinifera (Wang et al. 2002) and G. cruciata, respectively. The study by Kikuchi et al. (2006) confirmed that the response of stress-treated explants is relatively slow. It seems that not cryostorage, but primarily the prefreezing, slow dehydration treatment, is directly responsible for changes in embryogenic capacity. 
(Epi)genetic changes in regenerated plantlets

In our work, the sensitivity of detecting changes in both structure and methylation of DNA was studied by subjecting DNA preparations to digestion with restriction endonucleases, before AFLP analysis. The pairs of isoschisomers used were different in their sensitivity to methylation. We focused on monitoring the genetic uniformity of the 288 regenerants. We found only two new unique DNA fragments at the sequence DNA level after cryopreservation by encapsulation/dehydration. Our findings are consistent with earlier works which reported infrequent occurrences of genomic DNA alterations in plantlets recovered after cryopreservation. It was observed that the cryopreservation procedure did not generate additional variability to the initial diversity (Scocchi et al. 2004). The revealed genetic instability, among three cell lines of Oryza sativa (established from different mature embryos) and the corresponding re-established-afterfreezing calli, appears to be related to tissue-cultureinduced somaclonal variation (Moukadiri et al. 1999). In the majority of cases, the authors cite that these changes were evoked by in vitro culture procedures (Sales et al. 2001; Peredo et al. 2009; DeVerno et al. 1999; Moukadiri et al. 1999; Wang et al. 1994). DeVerno et al. (1999) found three unique RAPD fragments in two of six clones of embryogenic tissues re-established after cryopreservation, but not in the corresponding regenerants of Picea glauca. The genetic instability of cryopreserved embryogenic cell suspension culture of Festuca arundinacea and corresponding regenerated plants was confirmed by RAPD markers, using one of 19 different primers (Wang et al. 1994). Verification of PCR reactions ascertained that the sole difference observed is most likely due to the in vitro process. In other systems of plant regeneration, i.e. from already differentiated apical meristems, the number of new DNA fragments is also very limited. Martín and GonzálezBenito (2005), using the encapsulation/dehydration method of cryopreservation, showed different RAPD band patterns in 1 out of the 46 regenerants of Dendranthema grandiflora derived from cryopreserved shoot apex, whereas all 21 plantlets obtained by vitrification were genetically stable. Based on the AFLP markers, three extra DNA fragments were found between the control somatic embryos of Quercus suber and cryopreserved samples (Fernandes et al. 2008). These differences were not supported by SSR analysis. The relatively high levels of DNA structure changes after cryopreservation (9-14 alterations; up to $10.07 \%$ ) were described for two genotypes of Carica papaya (Kaity et al. 2008). For two other genotypes, the changes reached $1.5-2.84 \%$ (2 and 5 alterations), whereas the remaining two genotypes showed no changes.
Our studies show no differences between frozen- and non-frozen-PEM-derived regenerants on the DNA methylation level. Two new AFLP fragments detected in SC regenerants, whose DNA was digested with Acc65I/MseI, may be the reflection of DNA sequence changes. The methylation status of the genomic DNA was insignificantly different and reached 16.61-16.88\%. The lack of alterations in sequences of DNA methylation patterns in G. cruciata regenerants found support in the work of Johnston et al. They showed that epigenetic changes after cryopreservation may be temporary (Johnston et al. 2009). Methylation changes were observed in plant material following exposure to section, pre-culture, PVS2, and LN treatments (Kaity et al. 2008). However, occurrence and level of methylation modifications seem to be genotype or individual-dependent (Kaity et al. 2008; Channuntapipat et al. 2003; Johnston et al. 2009; Peredo et al. 2008, 2009). Altered methylation of DNA sequences have been found among the DNA of almond regenerants derived from shoot tips that were cryostored for 3 days, when compared with those that were cryostored for 24 months (Channuntapipat et al. 2003). The change was most likely due to different sub-culturing than to the cryopreservation process, because the initial explants had been taken from shoots that had been in in vitro culture for different lengths of time.

It is necessary to take into consideration that $G$. cruciata $\mathrm{NC}$ and SC regenerants originated from PEM, which, with reference to $\mathrm{LC}$, was exposed to 80 parallel subcultures during 1.5 years of culture. Almost all the NC and SC plantlets were grouped into one cluster by the UPGMA analysis. Despite of putting regenerants NC, SC and LC into separate clusters by PCoA (Fig. 5), approximate similarity between them may prove high genetic uniformity which was maintained during many years of suspension cultures, and high effectiveness of a 1.5-year-long cryostorage.

In conclusion, the present studies indicate the positive effect of cryotreatment on the embryogenic potential of G. cruciata suspension culture. Regenerants obtained from cryopreserved proembryogenic mass kept their genetic uniformity. Thus (1) simple and quick recovery of suspension cultures, (2) their high-embryogenic potential and (3) genetic uniformity of regenerants (irrespective of time cryostorage) are crucial factors to successful gentian cryopreservation.

Acknowledgments I would like to thank to Dr. P. T. Bednarek from the Plant Breeding and Acclimatization Institute, Radzików, Poland for providing us with the opportunity to perform molecular analysis and for his assistance with some of the statistics and drafting parts of the manuscript. This work was supported by the Polish Ministry of Science and Higher Education (Grant No. N302 3595 33). 
Open Access This article is distributed under the terms of the Creative Commons Attribution Noncommercial License which permits any noncommercial use, distribution, and reproduction in any medium, provided the original author(s) and source are credited.

\section{References}

Aguilar ME, Engelmann F, Michaux-Ferrière N (1993) Cryopreservation of cell suspensions of Citrus deliciosa Tan. and histological study. Cryo Letters 14:217-228

Ahuja S, Mandal BB, Dixit S, Srivastava PS (2002) Molecular, phenotypic and biosynthetic stability in Dioscorea floribunda plants derived from cryopreserved shoot tips. Plant Sci 163: 971-977

Bednarek P, Orłowska R, Koebner RMD, Zimny J (2007) Quantification of the tissue-culture induced variation in barley (Hordeum vulgare L.). BMC Plant Biol 7:10. doi:10.1186/1471-2229-7-10

Channuntapipat C, Sedgley M, Collins G (2003) Changes in methylation and structure of DNA from almond tissues during in vitro culture and cryopreservation. J Am Soc Hort Sci 128:890-897

DeVerno LL, Park YS, Bonga JM, Barrett JD (1999) Somaclonal variation in cryopreserved embryogenic clones of white spruce [Picea glauca (Moench) Voss.]. Plant Cell Rep 18:948-953

Dixit S, Mandal BB, Ahuja S, Srivastava PS (2003) Genetic stability assessment of plants regenerated from cryopreserved embryogenic tissues of Dioscorea bulbifera L. using RAPD, biochemical and morphological analysis. Cryo Letters 24:77-84

Engelmann F (2004) Plant cryopreservation: progress and prospects. In Vitro Cell Dev Biol Plant 40:427-433

Engelmann F, Lartaud M, Chabrillange N, Carron MP, Etienne H (1997) Cryopreservation of embryogenic calluses of two commercial clones of Hevea brasiliensis. Cryo Letters 18:107-116

Fernandes P, Rodriguez E, Pinto G, Roldán-Ruiz I, De Loose M, Santos C (2008) Cryopreservation of Quercus suber somatic embryos by encapsulation-dehydration and evaluation of genetic stability. Tree Physiol 28:1841-1850

Fiuk A, Rybczyński JJ (2007) The effect of several factors on somatic embryogenesis and plant regeneration in protoplast cultures of Gentiana kurroo (Royle). Plant Cell Tiss Org Cult 91:263-271

Fiuk A, Rybczyński JJ (2008) Factor influencing efficiency of somatic embryogenesis of Gentiana kurroo (Royle) cell suspension. Plant Biotechnol Rep 2:33-39

Häggman HM, Ryynänen L, Aronen T, Krajnakowa J (1998) Cryopreservation of embryogenic cultures of Scots pine. Plant Cell Tiss Org Cult 54:45-53

Hao YJ, Liu QL, Deng XX (2001) Effect of cryopreservation on apple genetic resources at morphological, chromosomal and molecular levels. Cryobiology 43:46-53

Hao YJ, You CX, Deng XX (2002a) Analysis of ploidy and the patterns of amplified fragment length polymorphism and methylation sensitive amplified polymorphism in strawberry plants recovered from cryopreservation. Cryo Letters 23:37-46

Hao YJ, You CX, Deng XX (2002b) Effects of cryopreservation on developmental competency, cytological and molecular stability of citrus callus. Cryo Letters 23:27-35

Harding K (2004) Genetic integrity of cyopreseved plant cell: review. Cryo Letters 25:2-22

Johnston JW, Benson EE, Harding K (2009) Cryopreservation induces temporal DNA methylation epigenetic changes and differential transcriptional activity in Ribes germplasm. Plant Physiol Biochem 47:123-131
Kaity A, Ashmore SE, Drew RA, Dulloo ME (2008) Assessment of genetic and epigenetic changes following cryopreservation in papaya. Plant Cell Rep 27:1529-1539

Kaity A, Ashmore SE, Drew RA (2009) Field performance evaluation and genetic integrity assessment of cryopreserved papaya clones. Plant Cell Rep 28:1421-1430

Kamada H, Ishikawa K, Saga H, Harada H (1993) Induction of somatic embryogenesis in carrot by osmotic stress. Plant Cell Tiss Org Cult 10:38-44

Kikuchi A, Sanuki N, Higashi K, Koshiba T, Kamada H (2006) Abscisic acid and stress treatment are essential for the acquisition of embryogenic competence by carrot somatic cells. Planta 223:637-645

Lardet L, Martin F, Dessailly F, Carron MP, Montoro P (2007) Effect of exogenous calcium on post-thaw growth recovery and subsequent plant regeneration of cryopreserved embryogenic calli of Hevea brasiliensis (Mull. Arg.). Plant Cell Rep 26:559-569

Martín C, González-Benito ME (2005) Survival and genetic stability of Dendranthema grandiflora Tzvelev shoot apices after cryopreservation by vitrification and encapsulation-dehydration. Cryobiology 51:281-289

Martín C, González-Benito ME (2009) DNA sequences of variable bands found after cryopreservation of chrysanthemum apices. In: Programme and abstracts, 1st international symposium "Cryopreservation in horticultural species", vol 28. Leuven, Belgia, 5-8 Apr 2009

Mikuła A (2006) Comparison of three techniques for cryopreservation and re-establishment of long-term Gentiana tibetica suspension culture. Cryo Letters 27:268-282

Mikuła A, Rybczyński JJ (2001) Somatic embryogenesis of Gentiana genus I. The effect of the preculture treatment and primary explant origin on somatic embryogenesis of Gentiana cruciata (L.), G. pannonica (Scop.) and G. tibetica (King). Acta Physiol Plant 23:15-25

Mikuła A, Fiuk A, Rybczyński JJ (2005a) Induction, maintenance and preservation of embryogenic competence of Gentiana cruciata L. cultures. Acta Biol Cracov Bot 47:227-236

Mikuła A, Rybczyński JJ, Skierski J, Latkowska MJ, Fiuk A (2005b) Somatic embryogenesis of Gentiana genus IV: Characterisation of Gentiana cruciata and Gentiana tibetica embryogenic cell suspensions. In: Hvolsef-Eide AK, Preil W (eds) Liquid culture systems for in vitro plant propagation. Springer, The Netherlands, pp 345-358

Mikuła A, Tykarska T, Kuraś M (2005c) Ultrastructure of Gentiana tibetica proembryogenic cells before and after cooling treatments. Cryo Letters 26:367-378

Mikuła A, Niedzielski M, Rybczyński JJ (2006) The use of TTC reduction assay for assessment of Gentiana spp. cell suspension viability after cryopreservation. Acta Physiol Plant 28:315-324

Mikuła A, Olas M, Sliwińska E, Rybczyński JJ (2008) Cryopreservation by encapsulation of Gentiana spp. cell suspensions maintains regrowth, embryogenic competence and DNA content. Cryo Letters 29:409-418

Moukadiri O, Lopes CT, Cornejo MJ (1999) Physiological and genomic variations in rice cells recovered from direct immersion and storage in liquid nitrogen. Physiol Plant 105:442-449

Peredo EL, Arroyo-García R, Reed BM, Revilla MÁ (2008) Genetic and epigenetic stability of cryopreserved and cold-stored hops (Humulus lupulus L.). Cryobiology 57:234-241

Peredo EL, Cires E, Arroyo-García R, Revilla MÁ (2009) Genetic and epigenetic stability of Humulus lupulus after in vitro culture. In: Proceedings of the scientific commission. International Hop Growers' Convention I.H.G.C. León, Spain, 21-25 June 2009, pp 64-67. http://www.lfl.bayern.de/ipz/hopfen/10585/sc09_ procceedings.pdf. Accessed 21 September 2010 
Rybczyński JJ, Mikuła A, Tomiczak K, Wójcik A, Fiuk A (2008) Biotechnology of gentians: the induction of embryogenic potential, its cryopreservation and utilization in somatic cell genetic manipulation. Physiol Plant 133:P07-P055

Sales E, Nebauer SG, Arrillaga I, Segura J (2001) Cryopreservation of Digitalis obscura selected genotypes by encapsulation-dehydration. Planta Med 67:833-838

Sánchez C, Martínez MT, Vidal N, San-José MC, Valladares S, Vieitez AM (2008) Preservation of Quercus robur germplasm by cryostorage of embryogenic cultures derived from mature trees and RAPD analysis of genetic stability. Cryo Letters 29:493-504

Scocchi A, Faloci M, Medina R, Olmos S, Mroginski L (2004) Plant recovery of cryopreserved apical meristem-tips of Melia azedarach L. using encapsulation/dehydration and assessment of their genetic stability. Euphytica 135:29-38

Tanaka M, Kikuchi A, Kamada H (2009) Isolation of putative embryo-specific genes using stress induction of carrot somatic embryos. Breed Sci 59:37-46

Urbanová M, Košuth J, Čellárová E (2006) Genetic and biochemical analysis of Hypericum perforatum L. plants regenerated after cryopreservation. Plant Cell Rep 25:140-147
Walters C, Wheeler L, Stanwood PC (2004) Longevity of cryogenically stored seeds. Cryobiology 48:229-244

Wang Z, He Y (2009) Effect of cryopreservation on the development and DNA methylation patterns of Arabidopsis thaliana. Life Sci J 6:55-60

Wang ZY, Legris G, Nagel J, Potrykus I, Spangenberg G (1994) Cryopreservation of embryogenic cell suspensions in Festuca and Lolium species. Plant Sci 103:93-106

Wang Q, Gafny R, Sahar N, Sela I, Mawassi M, Tanne E, Perl A (2002) Cryopreservation of grapevine (Vitis vinifera L.) embryogenic cell suspensions by encapsulation-dehydration and subsequent plant regeneration. Plant Sci 162:551-558

Winkelmann T, Mußmann V, Serek M (2004) Cryopreservation of embryogenic suspension cultures of Cyclamen persicum Mill. Plant Cell Rep 23:1-8

Zaghmout OMF, Torello WA (1992) Restoration of regeneration potential of long-term cultures of red fescue (Festuca rubra L.) by elevated sucrose levels. Plant Cell Rep 11:142-145 